\title{
Strength Characteristics and Slope Stability Analysis of Expansive Soil with Filled Fissures
}

\author{
Zhangjun Dai ${ }^{1, * \mathbb{D}}$, Jianhua Guo ${ }^{1,2}$, Hongming $\operatorname{Luo}^{1}{ }^{1}$, Jian Li ${ }^{1} \mathbb{D}$ and Shanxiong Chen ${ }^{1}$ \\ 1 State Key Laboratory of Geomechanics and Geotechnical Engineering, Institute of Rock and Soil Mechanics, \\ Chinese Academy of Sciences, Wuhan 430071, China; guojianhua17@mails.ucas.edu.cn (J.G.); \\ hmluo@whrsm.ac.cn (H.L.); lij@whrsm.ac.cn (J.L.); sxchen@whrsm.ac.cn (S.C.) \\ 2 University of Chinese Academy of Sciences, Beijing 100049, China \\ * Correspondence: zjdai@whrsm.ac.cn; Tel.: +86-13667217486
}

Received: 4 June 2020; Accepted: 1 July 2020; Published: 3 July 2020

\begin{abstract}
Fissured expansive soils were widely distributed in the South-to-North Water Transfer Project. Most of the fissures were filled with clay, which controlled the stability of the slope. With the method of layered filling — bevel cutting_refilling and a modular design idea, the sample with a filled fissure preparation device for triaxial test was designed. After setting the filled fissures of gray-green clay in the expansive soil, triaxial tests were carried out for the samples with no filled fissures and with filled fissures with inclination angles of $15^{\circ}, 30^{\circ}$, and $45^{\circ}$. Then, considering the spatial distribution and the strength of the filled fissures in the slope, the stability analysis method for the expansive soil slope with filled fissures was proposed. The stability of a typical slope in Nanyang was analyzed. The results show that the $c$ of expansive soil with filled fissures was about 12 to $15 \mathrm{kPa}$ and the $\varphi$ was $3^{\circ}$ to $6^{\circ}$. Filled fissures had an attenuation effect on the strength of the expansive soil. The larger the inclination of filled fissures, the more significant the effect of soil strength attenuation. The fissured slope stability was controlled by the filled fissures. The sliding surface was affected by the vertical fissures on the top of the slope and the slow-inclined long-large fissures in the slope, and the shape of the sliding surface was a broken line, which was basically consistent with the actual landslide.
\end{abstract}

Keywords: expansive soil; filled fissure; triaxial test; sample preparation device; strength characteristics; slope stability; sliding surface

\section{Introduction}

In expansive soil slope engineering, it has always been known that it will slide every time after cutting [1-3]. The mid-route of the South-to-North Water Transfer Project in China has a total length of over $1472 \mathrm{~km}$, among which expansive soil areas will cover about $340 \mathrm{~km}$. Expansive soils are mainly Middle Pleistocene alluvial and flood sedimentary clay, Lower Pleistocene flood sedimentary clay, and Neogene hard clay. Strong expansive soil is mainly distributed in the Xingtai-Handan area and Nanyang Basin. The instability of the expansive soil slope will seriously affect engineering construction and safe operation [4-7].

Fissures are one of the three major characteristics of expansive soil, and they are also the most intuitive and obvious feature in expansive soil engineering. The development of fissures complicates the strength characteristics of expansive soil [8-10]. The strength of the expansive soil is comprehensively controlled by the distribution, density, tendency, inclination, extension, and filling of the fissures, and the directional arrangement of the fissures causes the anisotropy of the strength of the expansive soil [11-13].

Due to the significant effect of fissures on the stability of expansive soil slopes, research on fissures in expansive soil has been carried out repeatedly [14-17]. A digital image acquisition system was 
employed to capture the evolution and propagation of fissures in the soil specimen subjected to desiccation [18]. The effect of the drying environment, i.e., temperature and relative humidity, on the engineering properties and the development of fissures of an expansive soil was investigated [19]. Suction measurements, free shrinkage tests, constrained shrinkage tests, and splitting tensile strength tests (STTs) were undertaken to investigate the shrinkage cracks in expansive soils [20]. The influential factors such as soil matric suction on the formation of surficial fissures and the stability of unsaturated soil slopes were studied [21]. The researchers divided the strength of expansive soil into the soil strength and the fissure surface strength, carried out direct shear and triaxial tests [22-24], and introduced CT scanning [23], image recognition and other methods [24] to quantitatively analyze the effect of fissures on the strength of expansive soil. These studies obtained some useful conclusions. Expansive soils swell in the presence of the water and shrink in its absence, thereby producing fissures which significantly alter their mechanical and hydraulic performance [18]. Fissures decrease the soil's strength and increase its hydraulic conductivity and compressibility [20]. However, there are still deficiencies. Most studies have not systematically classified and studied the fissure itself. Fissures in different sizes and states in the expansive soil have different effects on the engineering properties of expansive soil. If the fissures contain fillers, the engineering properties of the fillers also have a great influence on the strength of the expansive soil. The shape of the fissures in the expansive soil is random, and the shear plane in the direct shear test is difficult to extend completely along the fissure surface. In addition, when using undisturbed soil to make triaxial samples, the fissures are easily disturbed, and the shape of the fissures is not easy to control.

The limit equilibrium method [25,26] and finite element method [27] are commonly used to analyze the stability of unsaturated soil slope, which are suitable for the analysis of the stability of expansive soil slopes. Numerical analysis using the finite element method was conducted to analyze frequent shallow slope failures on highway embankments of expansive soil in the North Texas region [28]. The finite element method was used to study the effect of rainfall on the factor of safety of fill slopes constructed with expansive Yazoo clay soil in Mississippi [29]. A numerical exercise was performed on a slope in Regina, Canada, using a program that implemented the constitutive model into infinite slope formulation to reflect the influence of the stress regime change and associated softening on unsaturated expansive soil slope stability [30]. Major landslides that occurred on the mid-altitude slopes of Mount Elgon, eastern Uganda, were studied through the analyses of soil particle size distribution, Atterberg limits, shear strength and the factor of safety [31]. In the stability analysis of expansive soil slopes, the soil with fissures was usually homogenized [32]. In the analysis, the strength parameters obtained from the experiment were used as the overall strength parameters of the slope soil. On this basis, the stability of the slope was analyzed by reducing the strength parameters to reflect the influence of the fissures [33]. The calculated sliding surface of the slope was often arc-shaped (Figure 1a), and after surveying the 19 excavated channel landslides in the Nanyang section of the South-to-North Water Transfer Project, the landslides were mainly controlled by various fissures. The sliding surface was controlled by the vertical fissures at the trailing edge and the slow-inclined long-large filled fissures. The shape of the sliding surface was basically a broken line (Figure 1b).

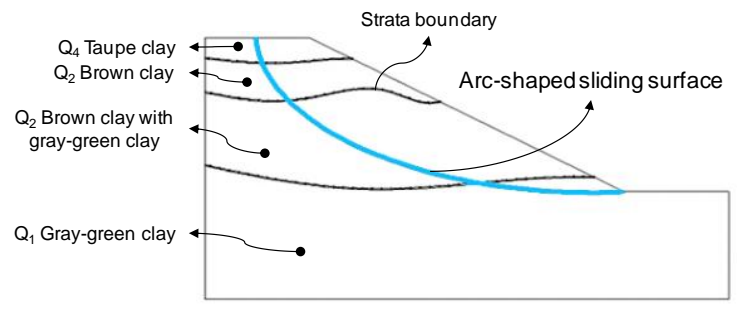

(a)

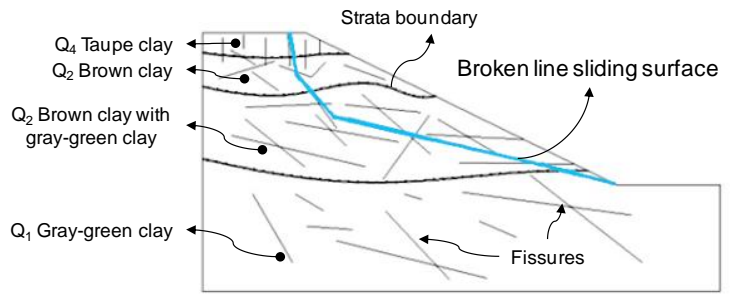

(b)

Figure 1. Conventional generalized sliding model and actual sliding model of expansive soil slope. (a) Arc-shaped sliding surface; (b) broken line sliding surface. 
It is impossible to objectively consider the characteristics of the fissures in expansive soil, especially the spatial distribution and strength of the fissures, when equivalent homogeneous soil was used to calculate the slope stability, and the effect of fissures on slope stability was reflected by strength attenuation. It was difficult to analyze how these fissures could constitute potential sliding surfaces $[34,35]$. Even if the strength parameter used in the calculation was the lowest strength of the fissure surface, for the actual slope, it was only correct when the sliding surface was along the fissure surface, which often resulted in the calculation parameters being too conservative and the safety factor was too small.

In this paper, a sample preparation device for preparing triaxial test samples with filled fissures was developed. Using the gray-green strong expansive soil in the Nanyang section of the South-to-North Water Transfer Project as the filling material and the brown medium expansive soil as the matrix of the expansive soil, triaxial samples with filled fissures were prepared. By carrying out triaxial tests, the strength properties of expansive soils with filled fissures are studied. On this basis, a slope stability analysis method that could reflect the impact of filled fissures, with calculation conditions which were close to the true state of the fissured expansive soil slope, was proposed, and the stability analysis of the fissured expansive soil slope was carried out. This method can provide a reference for solving the slope stability problem in the expansive soil distribution area.

\section{Morphology and Filling Characteristics of Fissures in Expansive Soil}

Based on the geological survey of the Nanyang section of the South-to-North Water Transfer Project, the most typical feature of the expansive soil was that the fissures were extremely developed, and the fissures contained a large amount of filler. The fissures of Nanyang expansive soil were basically filled fissures (Figure 2).

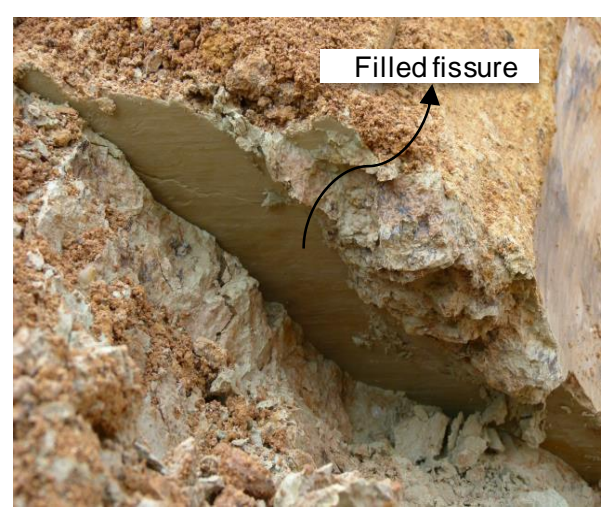

(a)

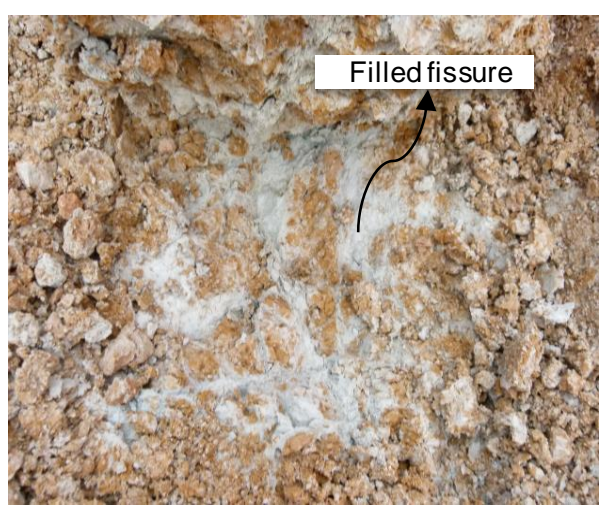

(b)

Figure 2. Filled fissures in the expansive soil. (a) Primary filled fissures; (b) secondary filled fissures.

Expansive soil fissures were widely distributed. According to the causes of fissures, combined with the distribution and the shape, they could be divided into primary fissures (Figure 2a) and secondary fissures (Figure 2b). The primary fissures were formed due to the uneven shrinkage stress in the soil. Since the shrinkage stress was proportional to the amount of water loss, the stress gradually decreased from the surface to the deep part of the soil. The primary fissures were often wide at the top and narrow at the bottom. They were basically filled with secondary clay and the fissure surface was smooth. The secondary clay was the clay deposited from the original site by wind and water to the distant location. It was gray-green clay in this area, which was deposited in the primary fissures under the action of a series of natural forces, forming the filling clay. Secondary fissures refer to tensile or shear fissures, which were formed due to changes in the external and internal stress conditions of the soil. Shear fissures and tensile fissures were widely distributed and dense. These fissures were irregular, short, and narrow. There was no obvious directionality, the fissure surface was relatively rough, and it was often filled with gray-green clay. The filling clay contained more clay minerals, such 
as montmorillonite and illite, and had a more dense structure, higher content of fine particles, lower permeability and higher plasticity. The expansion of the filling was stronger than that of the original expansive soil, and the engineering properties were extremely poor. The secondary fissure gradually developed into the long-large fissure under the influence of atmospheric camping forces and other factors, and its influence on the slope gradually approached that of the original fissure.

The groundwater activity in the expansive soil area was frequent, and most of the fissures in the soil were filled with gray-green clay, and the rest of the fissures were filled with calcium and iron-manganese. The number of unfilled fissures was very small. During the deposition process, the soil crept repeatedly under the action of expansion. Because the creeping effect had a sorting and rounding effect on the soil particles, the fissure surface was often very smooth and had a waxy luster, which was the natural weak surface in the soil. In addition, due to these special deformation characteristics, such fissures were often active areas of water movement, and soils often appeared gray-green after leaching. The filling was formed by the ion exchange or mineral deposition of the clay minerals such as montmorillonite and illite in the expansive soil during the migration of groundwater through the fissures. The content of clay particles and hydrophilic minerals in the filler was extremely high, and the filling gray-green clay was very delicate, and the moisture content was large.

The investigation showed that the filled fissures of weak expansive soil accounted for $64.3 \%$ to $83.9 \%$ of the total fissures. The filled fissures of gray-green clay in the medium expansive soil area had vertical zoning characteristics, and the filled fissures within $6 \mathrm{~m}$ depth account for about $80 \%$ of the total fissures. However, the development of filled fissures in strong expansive soils was more significant, accounting for more than $90 \%$ of the total fissures. The filling was irregularly distributed in the soil in a net shape. The filling thickness was generally 2 to $5 \mathrm{~cm}$. This was in the form of a film or lens, and the local thickness was more than $10 \mathrm{~cm}$.

$\mathrm{Lu}$ [36] conducted engineering geological mapping and statistics of structural surface morphology on the channel slopes of the Nanyang section of the South-to-North Water Transfer Project, and found that the fissures had a certain direction, and the fissures were clear and smooth, with waxy luster and scratches, and were mostly filled with clay. At the foot of some landslides, long-large fissures were exposed along the slope with a slow dip angle. The dip angle was $7^{\circ}$ to $17^{\circ}$. The length were generally more than $20 \mathrm{~m}$ and the thickness was even more than $40 \mathrm{~cm}$. Zhao [37] made statistics on the occurrence of fissures in Nanyang expansive soil, and found that the soil fissures were dominated by slow and medium dip angles, both of which accounted for $96.7 \%$ of the total fissures, while steep dip angle fissures were very few in number, accounting for only $3.3 \%$ (Table 1 ). At the same time, the inclination of the fissure had a correlation with its extension scale. The longer the extension of the fissure, the higher the proportion of the slow inclination fissure.

Table 1. Statistical table of fissure dip angle of Nanyang expansive soil [37].

\begin{tabular}{|c|c|c|c|c|c|c|}
\hline \multirow[t]{2}{*}{ Fissure Classification } & \multicolumn{2}{|c|}{$\begin{array}{c}\text { Slow Dip Angle } \\
\left(\leq 30^{\circ}\right)\end{array}$} & \multicolumn{2}{|c|}{$\begin{array}{l}\text { Medium Dip Angle } \\
\qquad\left(30^{\circ}-60^{\circ}\right)\end{array}$} & \multicolumn{2}{|c|}{$\begin{array}{l}\text { Steep Dip Angle } \\
\left(\geq 60^{\circ}\right)\end{array}$} \\
\hline & Count & Proportion & Count & Proportion & Count & Proportion \\
\hline Long-large fissure & 917 & $66.7 \%$ & 449 & $32.7 \%$ & 8 & $0.6 \%$ \\
\hline Large fissure & 345 & $37.2 \%$ & 528 & $56.8 \%$ & 56 & $6.0 \%$ \\
\hline Small fissure & 15 & $14.0 \%$ & 78 & $72.9 \%$ & 14 & $13.1 \%$ \\
\hline Total & 1277 & $53.0 \%$ & 1055 & $43.7 \%$ & 78 & $3.3 \%$ \\
\hline
\end{tabular}

Long-large fissures often extended more than $2 \mathrm{~m}$ in length, and the longest reached nearly $100 \mathrm{~m}$. Many long-large fissures were rich in low-strength filled clay and formed weak structural planes. They often directionally penetrated the slope with a small inclination angle, which controlled the stability of the expansive soil slope. When this kind of filled fissure was developed in the slope and the tendency was the same as that of the slope, the impact on the slope stability was very significant. A large number of on-site landslide investigations showed that the expansive soil landslides were basically cut out along the fissures at the leading edge, forming the lower edge of the sliding surface. 


\section{Experimental Study on Strength Characteristics of Expansive Soil with Filled Fissures}

\subsection{Sample Preparation Device}

At present, in order to study the mechanical characteristics of the filled fissures of the expansive soil, the triaxial test was usually carried out using the original sample. In actual operation, the following deficiencies still existed.

1. The success rate of cutting the sample by using the original sample was low, the adhesion between the expansive soil and the filled fissure was weak, and it was easy to break along the fissure during the cutting process.

2. The sample preparation process had a large disturbance to the filled fissures of the expansive soil, the filling material was easy to break and fissure, and the bonding conditions and closed state of the in situ filled fissures were changed.

3. It was difficult to control the spatial distribution of the filled fissures. Since a group of triaxial tests often required 3 to 4 parallel samples, the filled fissure distribution of each sample was difficult to keep consistent, resulting in test errors.

In view of the above deficiencies, based on the conventional triaxial test sample preparation method, the mold was improved, the strong expansion fissure filler was manually placed in the sample, and the thickness and the inclination angle of the filled fissure were controlled. The layered filling - bevel cutting — refilling was the basic idea of the sample preparation device and method.

A sample preparation device for triaxial test sample containing a filled fissure was designed (Figure 3). The sample preparation device included a base and a mold fixing component, a sample pushing and positioning component, and a sample mold. The base of the device was a gate-shaped structure welded by steel plates. The center of the top plate was provided with a hole as a channel for pushing the sample. The threaded pushing screw was concentric with the hole, and there were two screws on each side of the top surface of the base to fix the mold. A positioning ruler was provided on the inner side of the base, together with a locator fixed at the bottom of the pushing screw to form the positioning component, the driving wrench was fixed at the bottom of the pushing screw, and the pushing screw was moved up and down by twisting the driving wrench to push the sample. The sample mold was composed of upper general mold, lower general mold, upper inclined mold and lower inclined mold with an inner diameter of $39.1 \mathrm{~mm}$. The device adopted the modular design, and it could control the inclination of filled fissures by changing the mold, which was simple and easy to operate.

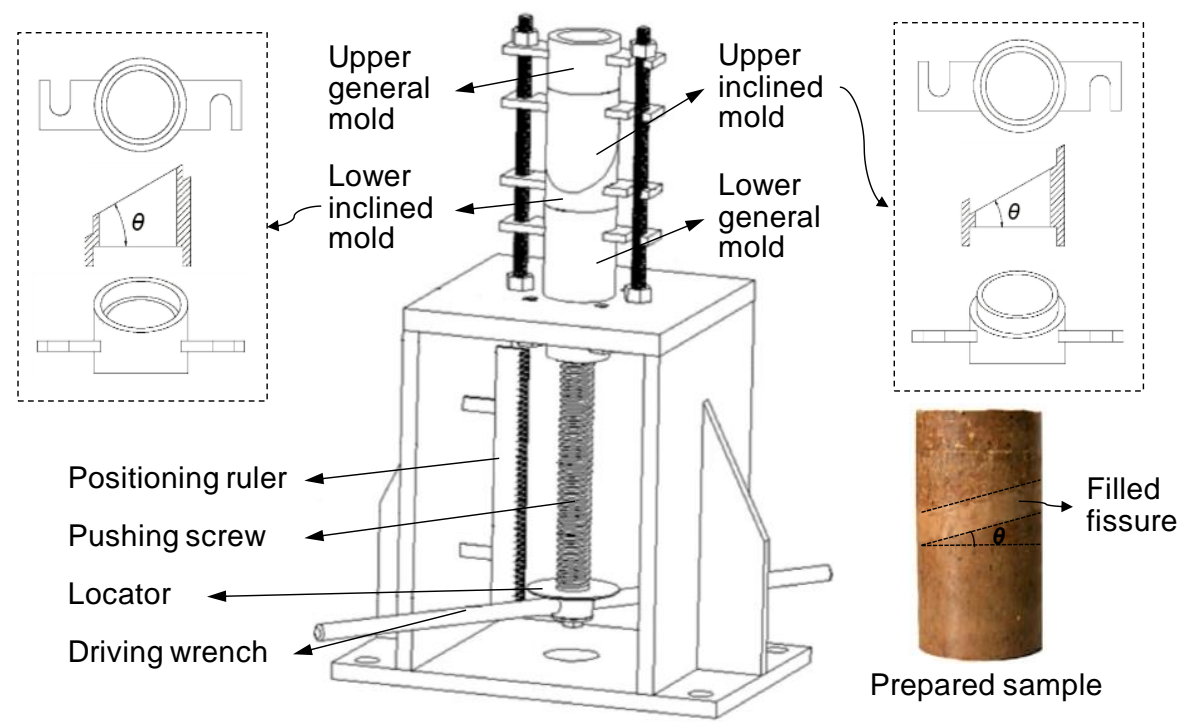

Figure 3. Sample preparation device for triaxial sample with filled fissure. 


\subsection{Sample Preparation Method}

The sample preparation steps were as follows.

1. Applied petroleum jelly on the inner sides of all the molds and installed the lower general mold to form a cylindrical mold with an inner diameter of $39.1 \mathrm{~mm}$.

2. According to the volume of the mold and the moisture content and density of the expansive soil, the amount of the expansive soil was calculated. Filled the lower general mold with the expansive soil matrix and compacted it layer by layer, and scraped the top surface. At this time, the height of the sample was the maximum height of the sample under the filled fissure (Figure $4 \mathrm{a}$ ).

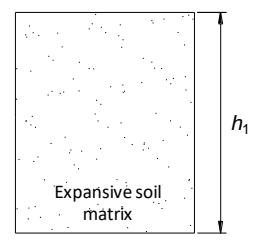

(a)

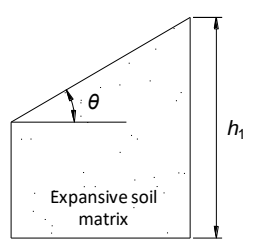

(b)

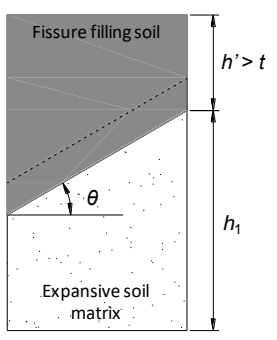

(c)

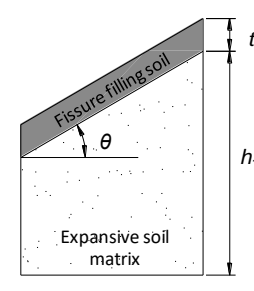

(d)

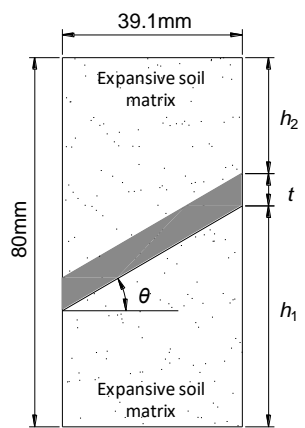

(e)

Figure 4. The sample preparation steps. (a) Expansive soil matrix filled and compacted; (b) expansive soil matrix with a certain inclined top surfaces; (c) fissure filling soil filled and compacted until the height exceeded the top of the filled fissure; (d) sample cutting to form a filled fissure with a certain inclination; (e) expansive soil matrix filled and compacted to complete the sample.

3. Installed the lower inclined mold, twisted the driving wrench to push the expansive soil matrix in the lower general mold to the top surface flush with the highest point of the lower inclined mold, and cut the soil along the top surface of the lower inclined mold to form the samples with a certain inclined top surfaces (Figure 4 b).

4. Installed the upper inclined mold and the upper general mold, and filled the fissure filling soil in the mold and compacted it so that the sample height exceeded the height from the bottom of the sample to the top of the filled fissure (Figure 4c).

5. Twisted the driving wrench to move down the thickness of the filled fissure, pressed the sample down to the bottom of the mold, removed the upper inclined mold and the upper general mold, and cut the sample along the top surface of the lower inclined mold to form a filled fissure with a certain inclination (Figure $4 \mathrm{~d}$ ). At this time, the preparation of the filling fissure and the expansive soil matrix at the bottom of the sample was completed.

6. Installed the upper inclined mold and the upper general mold, and filled the mold with the expansive soil matrix and compacted it so that the top surface of the sample reached the sample height, i.e., $80 \mathrm{~mm}$ (Figure 4e).

7. Twisted the driving wrench to push out the sample to complete the sample preparation.

\subsection{Test Equipment and Materials}

Taking the thickness and inclination of the filled fissure as control conditions, the triaxial tests of the expansive soil with filled fissure were carried out. The TSZ30-2.0 strain control triaxial apparatus produced by Nanjing Soil Instrument Factory was used. The diameter of the triaxial sample was 39.1 $\mathrm{mm}$, the cross-sectional area was $12 \mathrm{~cm}^{2}$, and the height was $80 \mathrm{~mm}$. The matrix of the expansive soil in the sample was the brown medium expansive soil in the Nanyang section of the South-to-North Water Transfer Project, and the fissure filling soil was the scraped gray-green clay in the primary fissures 
of the strong expansive soil in the Nanyang section. The basic physical properties of the sample are shown in Table 2.

Table 2. Basic physical properties of the soils in the sample.

\begin{tabular}{|c|c|c|c|c|c|c|c|}
\hline \multirow{2}{*}{ Soil Type } & \multirow{2}{*}{ Moisture Content (\%) } & \multirow{2}{*}{ Density $\left(\mathrm{g} / \mathrm{cm}^{3}\right)$} & \multicolumn{2}{|c|}{ Particle Composition (\%) } & \multirow{2}{*}{$\begin{array}{c}\text { Liquid } \\
\text { Limit (\%) }\end{array}$} & \multirow{2}{*}{$\begin{array}{c}\text { Plastic } \\
\text { Limit (\%) }\end{array}$} & \multirow{2}{*}{$\begin{array}{c}\text { Free Expansion } \\
\text { Rate (\%) }\end{array}$} \\
\hline & & & Silt & Clay & & & \\
\hline $\begin{array}{l}\text { Filled } \\
\text { fissure }\end{array}$ & 31.56 & 1.93 & 7 & 93 & 90.11 & 29.46 & 110 \\
\hline Soil matrix & 22.12 & 1.92 & 19 & 81 & 57.32 & 23.05 & 70 \\
\hline
\end{tabular}

\subsection{Test Method}

In this test, the mechanical properties of expansive soil with filled fissures of different inclination angles under a certain thickness were studied. Samples were manually prepared with filled fissures with inclination angles of $15^{\circ}, 30^{\circ}$, and $45^{\circ}$, and with a thickness of $7 \mathrm{~mm}$, and the sample without filled fissures was prepared with the same medium expansive soil for comparison.

After sampling on site, the soil was dried, ground, and passed through a $0.05 \mathrm{~mm}$ sieve, prepared according to the measured moisture content, placed in a closed container and left to stand for $24 \mathrm{~h}$ to ensure that the soil moisture was evenly distributed. The filling soil had a moisture content of $32 \%$ and a wet density of $1.93 \mathrm{~g} / \mathrm{cm}^{3}$, and the soil matrix had a moisture content of $28 \%$ and a wet density of $1.92 \mathrm{~g} / \mathrm{cm}^{3}$.

Four samples were taken from each group and tested at confining pressures of 100, 150, 200, and $250 \mathrm{kPa}$. The samples were saturated during the test, and the shear rate was $0.015 \mathrm{~mm} / \mathrm{min}$. The consolidated undrained (CU) triaxial test was conducted to study the effect of filled fissures with different inclination angles on the strength characteristics of the expansive soil.

\section{Analysis of Strength Characteristics of Expansive Soil with Filled Fissures}

\subsection{Analysis of Stress-Strain Curve and Deformation Characteristics}

Figure 5 shows the typical failure modes of triaxial sample without a filled fissure, and triaxial samples with a filled fissure with an inclination angle of $15^{\circ}, 30^{\circ}$ and $45^{\circ}$. The stress-strain curve of each sample is shown in Figure 6.

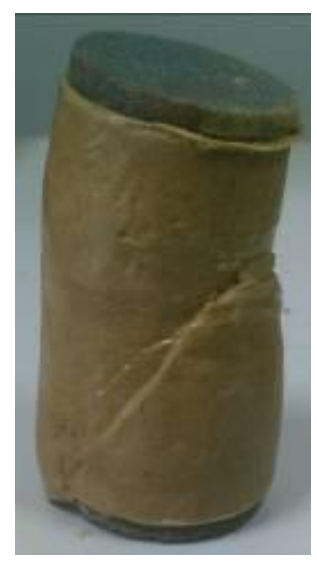

(a)

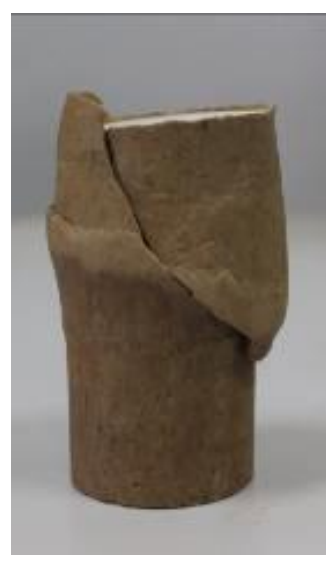

(b)

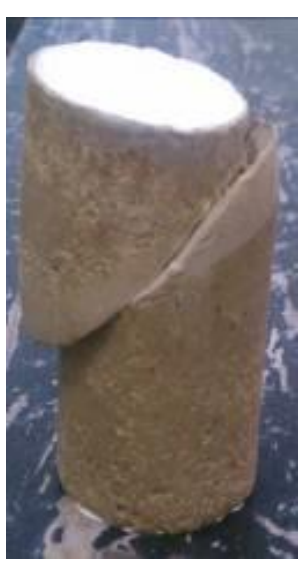

(c)

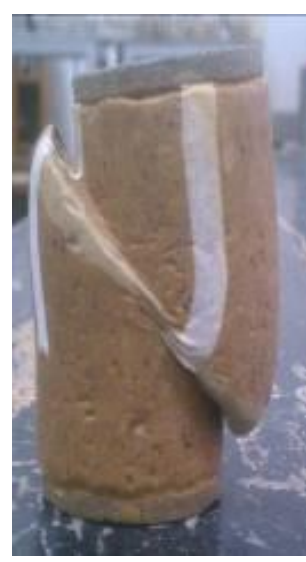

(d)

Figure 5. Failure modes of the triaxial samples. (a) Without a filled fissure; (b) filled fissure with an inclination angle of $15^{\circ}$; (c) filled fissure with an inclination angle of $30^{\circ}$; (d) filled fissure with an inclination angle of $45^{\circ}$.

The failure mode of the soil without a filled fissure was a typical triaxial test failure mode, and shear failure occurred at an angle of approximately $45^{\circ}+\varphi / 2$ to the horizontal direction of the sample. The deformation of the expansive soil was strain hardening. The shear stress increased rapidly after 
the test started. When the strain reached about $5 \%$, the growth rate gradually slowed down, the sample began to fail, and the shear stress quickly reached the peak value. After that, the shear stress remained basically stable, and the deformation of the soil appeared as plastic sliding along the shear surface. This strain hardening characteristic became more and more significant as the confining pressure increased.

The failure of a sample with a filled fissure of $15^{\circ}$ inclination angle was similar to that of a sample without a filled fissure, but bulging deformation occurred near the filled fissure. The reason for this was that the strength of the fissure filling clay was lower than that of the soil matrix. When the sample was subjected to axial partial stress, a large deformation first occurred in the weak part. When this deformation developed to a certain extent, the upper and lower expansive soil matrix gradually approached, and the filling clay lost the space for lateral deformation. The deformation characteristics of the sample gradually approached the state of sample without fissure, and the failure mode of the conventional triaxial test appeared. The shear plane did not develop along the $15^{\circ}$ slow-inclined fissure, but remained at the theoretical $45^{\circ}+\varphi / 2$, and then the failure characteristics of shear plane cutting and filling fissures appear. This shows the failure characteristics of shear plane cutting the filled fissure. The stress-strain curve showed a certain degree of downward movement, indicating that the filled fissure had an attenuating effect on the strength of the soil. Under low confining pressure, the downward movement amplitude was small, which was basically the same as that of no filled fissure. With the increase in confining pressure, the downward movement was getting larger and larger. At the load level of $250 \mathrm{kPa}$, the ultimate strength of the sample without a filled fissure was close to $300 \mathrm{kPa}$, while the strength of the sample with $15^{\circ}$ inclination was close to $200 \mathrm{kPa}$. The deformation was still strain hardening.

After the sample with a $30^{\circ}$ inclination filled fissure was destroyed, its shear plane was fully developed in the $7 \mathrm{~mm}$-thick filled fissure. The shear plane was not parallel to the $30^{\circ}$ inclined plane, but developed from the upper section at one end of the filled fissure, and passed through the fissure diagonally, cut out from the lower section of the filled fissure, and its inclination was slightly greater than $30^{\circ}$, and it was closer to the inclination of the shear plane of the theoretical analysis. Figure 7 shows the shear failure characteristics of the sample along the diagonal of the filled fissure.

Compared with the result of the sample with a $15^{\circ}$ inclination filled fissure, the stress-strain curve of the sample with a $30^{\circ}$ inclination filled fissure moved downwards overall, but it still showed a lower downward amplitude under low confining pressure. As the confining pressure level increased, the amplitude of the curve downward increased. At the load level of $250 \mathrm{kPa}$, the ultimate strength of the sample with a $15^{\circ}$ inclination filled fissure was close to $300 \mathrm{kPa}$, while the strength of the sample with a $30^{\circ}$ inclination filled fissure was close to $150 \mathrm{kPa}$. The deformation of the samples still showed strain hardening.

For the sample with a $45^{\circ}$ inclination filled fissure, the shear plane still retained the failure characteristics of the sample with a $30^{\circ}$ inclination filled fissure, but at this time, the inclination angle of the filled fissure was already large and the shear plane was basically parallel to the filling fissures, and the actual shear plane inclination was greater than $45^{\circ}$. Compared with the test results of the previous samples, the stress-strain curve changed significantly, showing a change from strain hardening to strain softening, and also showing a certain brittleness. In addition, the peak strength was greatly improved, which was almost close to the test results of the sample with $15^{\circ}$ inclination filled fissure, but it still showed a decay trend in the later stage of deformation compared with the previous groups of tests, and the strength in the later stage was stable between 100 and $150 \mathrm{kPa}$. 


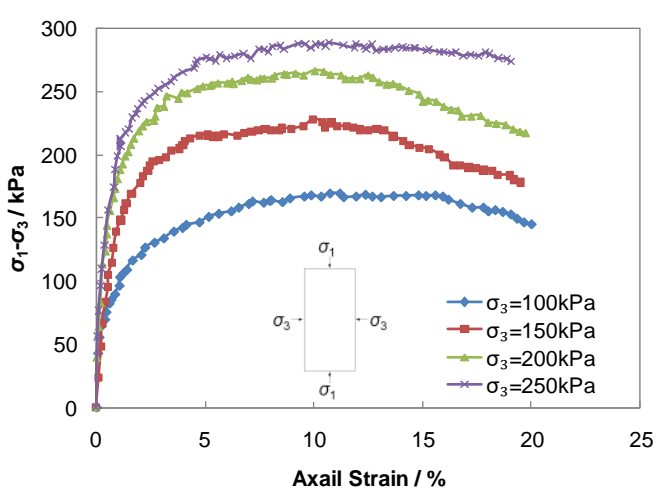

(a)

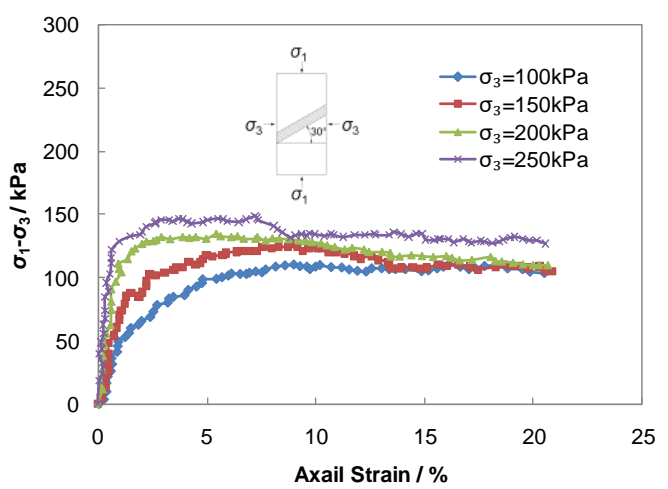

(c)

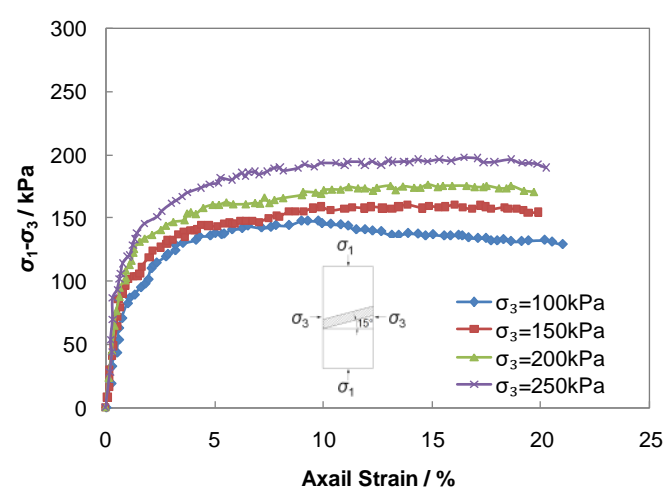

(b)

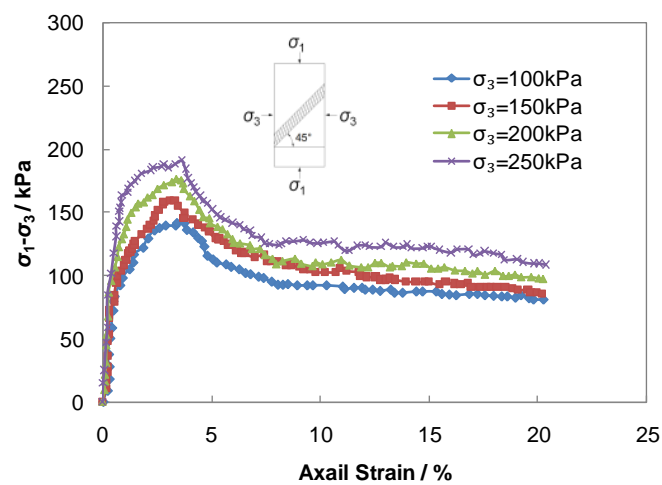

(d)

Figure 6. Stress-strain curve of the triaxial test. (a) Without a filled fissure; (b) filled fissure with an inclination angle of $15^{\circ}$; (c) filled fissure with an inclination angle of $30^{\circ}$; (d) filled fissure with an inclination angle of $45^{\circ}$.

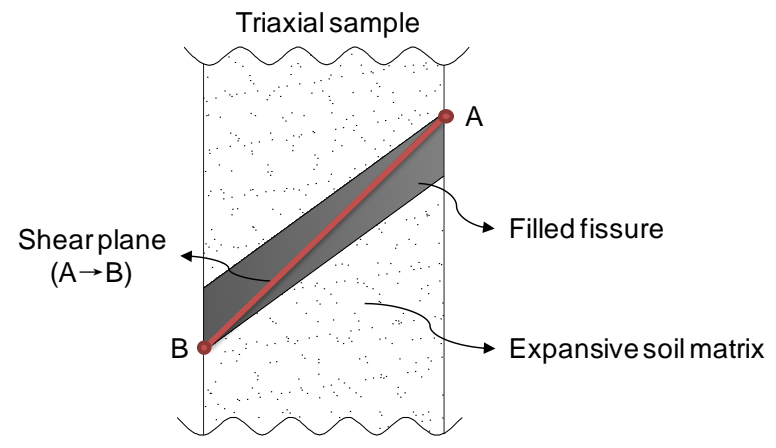

Figure 7. The shear failure characteristics of the sample along the diagonal of the filled fissure.

\subsection{Strength Fitting Method and Strength Characteristic Analysis}

According to the stress-strain relationship curve of the triaxial test results, the peak stress $\left(\sigma_{1 f}-\sigma_{3 f}\right)$ of the specimen at failure was obtained. According to the static equilibrium conditions, Equations (1) and (2) were used to calculate the normal stress $\sigma_{n}$ and shear stress $\tau$ in the filled fissure when the specimen failed [38].

$$
\sigma_{n}=\frac{\left(\sigma_{1 f}+\sigma_{3 f}\right)}{2}+\frac{\left(\sigma_{1 f}-\sigma_{3 f}\right)}{2} \cos 2 \alpha
$$




$$
\tau=\frac{\left(\sigma_{1 f}-\sigma_{3 f}\right)}{2} \sin 2 \alpha
$$

where $\sigma_{n}$ is the normal stress on the shear plane, $\tau$ is the shear stress on the shear plane, $\sigma_{1 f}$ is the large peak principal stress, $\sigma_{3 f}$ is the small peak principal stress, and $\alpha$ is the angle between the shear plane and the horizontal plane.

According to the Mohr-Coulomb theory, the relationship curve between normal stress $\sigma_{n}$ and shear stress $\tau$ could be obtained, and the shear strength parameters $c$ and $\varphi$ of the filled fissure can be obtained. The fitting results are shown in Figure 8 and Table 3, respectively.

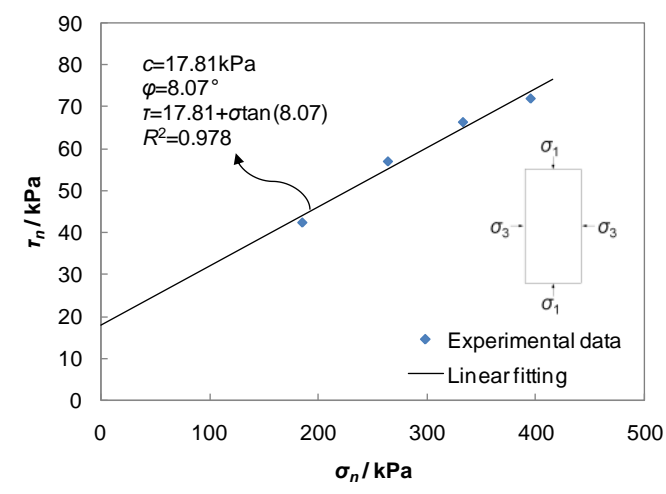

(a)

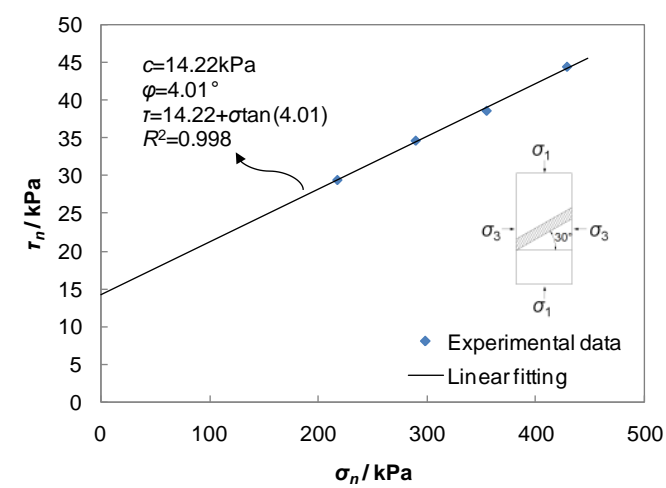

(c)

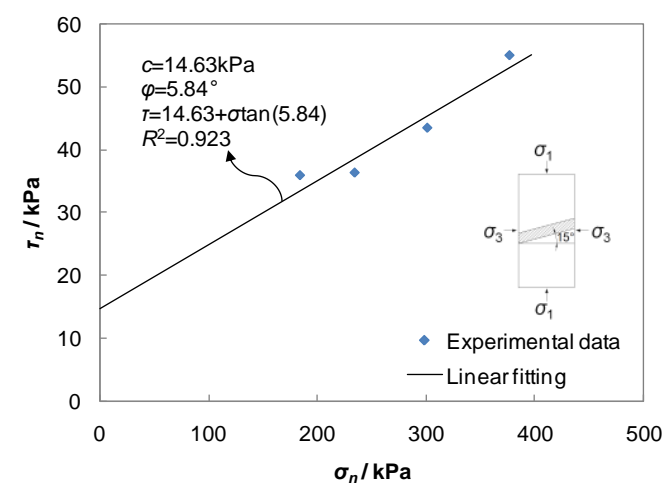

(b)

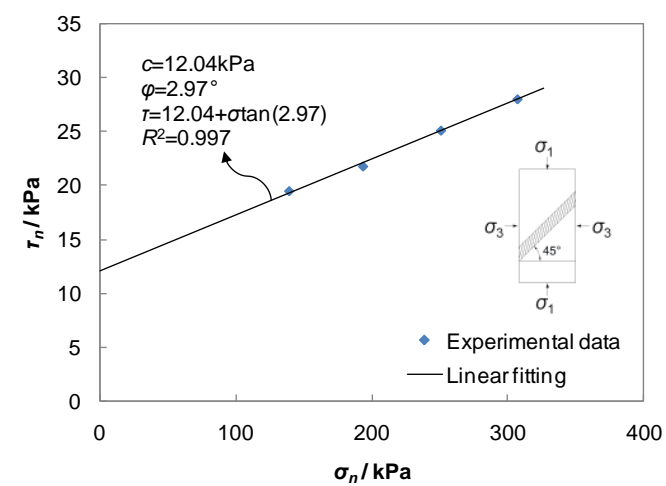

(d)

Figure 8. Shear strength fitting results of the triaxial test. (a) Without a filled fissure; (b) filled fissure with an inclination angle of $15^{\circ}$; (c) filled fissure with an inclination angle of $30^{\circ}$; (d) filled fissure with an inclination angle of $45^{\circ}$.

Table 3. Shear strength results of the triaxial test.

\begin{tabular}{ccccc}
\hline \multirow{2}{*}{ Shear Strength } & \multicolumn{4}{c}{ Inclination Angle of the Filled Fissure $\left(^{\circ}\right.$ ) } \\
\cline { 2 - 5 } & No Filled Fissure & $\mathbf{1 5}$ & $\mathbf{3 0}$ & $\mathbf{4 5}$ \\
\hline $\mathcal{c}(\mathrm{kPa})$ & 17.81 & 14.63 & 14.22 & 12.04 \\
$\varphi\left({ }^{\circ}\right)$ & 8.07 & 5.84 & 4.01 & 2.97 \\
\hline
\end{tabular}

It can be seen that the homogeneous medium expansive soil matrix was used for the triaxial test, and the strength parameter $c=17.81 \mathrm{kPa}$ and $\varphi=8.07^{\circ}$. After setting the filled fissures of gray-green strong expansive soil in the medium expansive soil matrix, it had a greater impact on the mechanical properties of the expansive soil, resulting in different degrees of strength attenuation at various load levels in the triaxial tests. The strength attenuation was positively correlated with the inclination of the filled fissure. The strength parameters of expansive soils with filled fissures were basically stable, in which the cohesive force $c$ was about 12 to $15 \mathrm{kPa}$ and the internal friction angle $\varphi$ was about $3^{\circ}$ to 
$6^{\circ}$. The deformation characteristics of the samples had a tendency to develop from strain hardening to strain softening after setting the filled fissures, and this was most significant when the fissure was filled with a $45^{\circ}$ inclination angle.

\section{Stability Analysis of Expansive Soil Slope Considering Filled Fissures}

\subsection{Engineering Geological Survey of the Landslide}

The landslide in Nanyang section of the middle route of the South-to-North Water Transfer Project was selected as an example to analyze the slope stability (Figure 9a). The Nanyang section was located in the southern part of the South-to-North Water Transfer Project and was a typical strong expansive soil distribution area. The expansive soils in the area were mainly Middle and Lower Pleistocene flood sedimentary clays, and Neogene lacustrine sedimentary clays, including brown clay and gray-green clay.

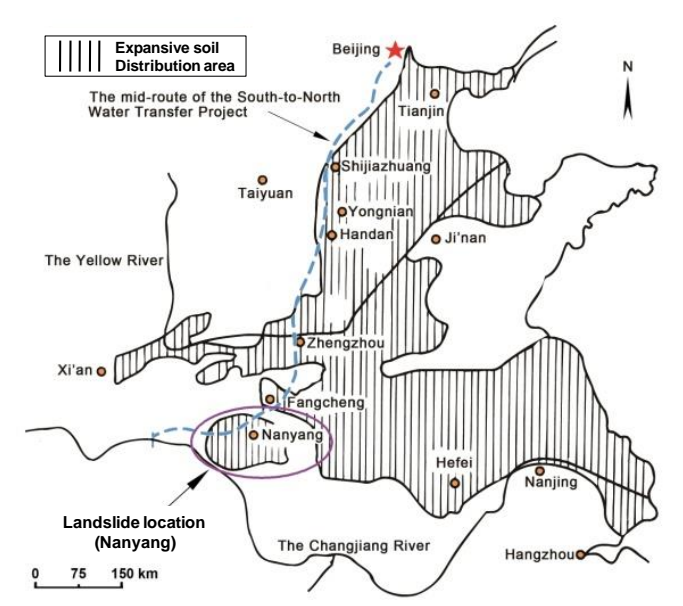

(a)

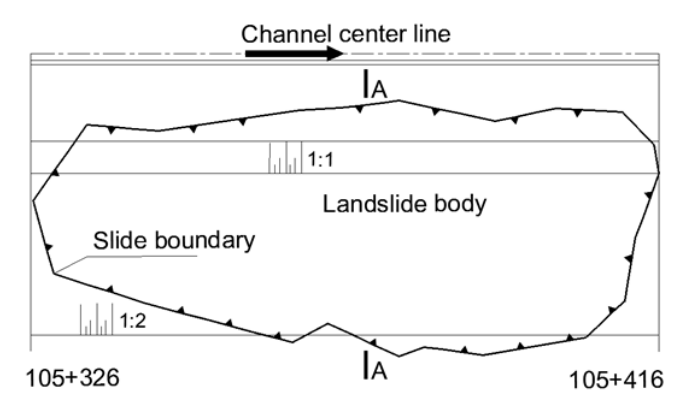

(b)

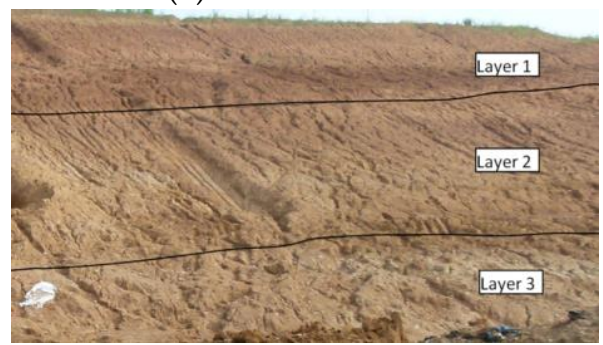

Reddish brown clay

Brown-yellow clay

Brown clay and gray-

green clay

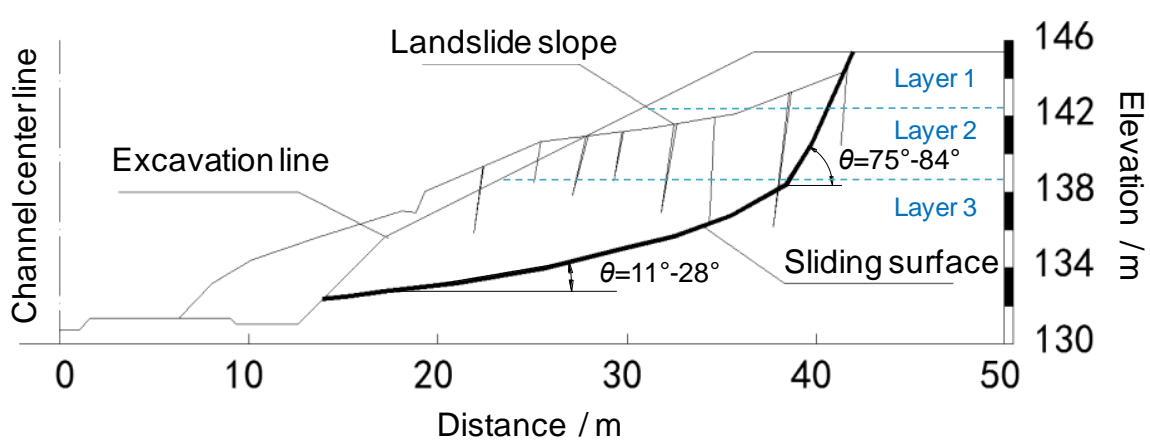

(c)

Figure 9. The landslide characteristics. (a) Site location; (b) landslide plan; (c) landslide profile and landslide engineering geological information.

The landslide was located in the medium expansive soil area, the original slope ratio was 1:2, the top elevation of the slope was $145.695 \mathrm{~m}$, and the bottom elevation was $131.384 \mathrm{~m}$. 
The formation was the Middle Pleistocene alluvial $\left(\mathrm{Q}_{2}{ }^{\mathrm{al}+\mathrm{pl}}\right)$ clay, and according to the detailed geological survey on site, it was found that the slope could be divided into three layers (Figure 9c). The first layer of the landslide was reddish brown clay containing a small amount of iron manganese nodules-the thickness was about $3 \mathrm{~m}$. The second layer was brown-yellow clay with a thickness of about $4 \mathrm{~m}$, and the content of calcium nodules and black iron manganese nodules was low. The third layer was brown clay and gray-green clay, containing some black iron manganese nodules.

The sliding direction of the landslide was $130^{\circ}$, and the total length of the landslide body was about $38.48 \mathrm{~m}$. The trailing edge of the landslide was generally vertical, with a length of about $3.4 \mathrm{~m}$. The left side of the landslide was heavily deformed and severely broken. The maximum height of the steep sill was $1.8 \mathrm{~m}$, and the height of the right side was 0.2 to $0.8 \mathrm{~m}$. The front edge of the landslide cut out along the bedding gentle fissure at the slope foot. The landslide profile is shown in Figure 9.

Geology cuts were arranged on both sides of the slope and fissures were recorded. It was concluded that there were 105 fissures in the length of $L>1.0 \mathrm{~m}$ in the slope. The fissures developed mainly in two groups, and they were mainly low inclination fissures, followed by medium inclination. One group of along-slope fissures had the tendency of $120^{\circ}$ to $140^{\circ}$ and the inclination of $5^{\circ}$ to $50^{\circ}$, the other group of anti-slope fissures had the tendency of $310^{\circ}$ to $325^{\circ}$ and the inclination of $3^{\circ}$ to $60^{\circ}$.

The steep inclination fissures along the slope developed in the upper part of the slope, the inclination angle was $75^{\circ}$ to $84^{\circ}$, and the fissure surfaces were flat and smooth, filled with gray-green clay. At the foot of the slope, low inclination angle fissures along or against the slope developed, the inclination angle was $11^{\circ}$ to $28^{\circ}$, and the fissure surfaces were also flat and smooth, filled with gray-green clay.

\subsection{Slope Generalization and its Stability Analysis}

The stability analysis of slope was carried out by using the platform Slide, which is the two-dimensional limit equilibrium process for the evaluation of the rock and soil slope safety coefficient and failure probability. Three limit equilibrium methods, namely Janbu correction, Spencer and Morgenstern, which could meet inter slice force and moment equilibrium and were suitable for a broken line slide surface, were chosen for slope stability calculation.

According to the actual slope, the 2D geometry model of the slope was established. The vertical fissures at the top of the slope and the controlled fissures in the slope body were converted into thin layers in the model, and the mechanical strength parameters of the thin layers were considered to reflect the influence of the fissures on the slope stability. The thickness of the thin layer was selected as the average thickness of the measured fissure. According to the measured statistics, the thickness of the fissure was generally 3 to $8 \mathrm{~cm}$. Therefore, the following methods were used to generalize the spatial distribution of fractures

Firstly, the slope surface equation was established in the plane coordinate system.

$$
y=a x+b, x \in(m, n)
$$

For the fissure distributed in the elevation $h$, with the inclination angle of $\theta$, the length of $l$, and the thickness of $t$, the coordinate at the endpoint in the slope surface was $[(h-b) / a, h]$. In the model, the fissure was simplified to a linear form, and the equation could be expressed as follows.

$$
y=\tan \theta\left(x-\frac{h-b}{a}\right)+h, x \in\left(\frac{l}{\sqrt{1+\tan ^{2} \theta}}\right)+\frac{h-b}{a}, \frac{h-b}{a}
$$

In the actual modeling, through the preparation of the program, the fissure Equation (4) was translated upward by the fissure thickness $t$, and the intersection point with the slope Equation (3) is obtained to obtain the coordinates of the four vertices of the parallelogram fissure. The geometric model of slope fissure surface distribution is basically consistent. These coordinates were imported 
into the slope model to establish the geometric model of the slope with filled fissures. The calculation model is shown in Figure 10.

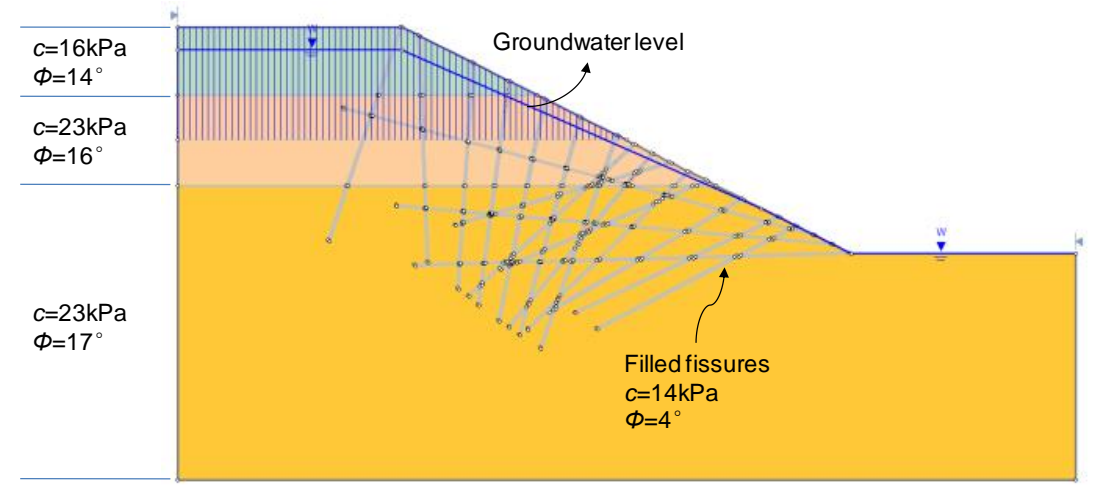

Figure 10. The calculation model of the slope.

In situ direct shear tests were carried out on the slope soil, and indoor triaxial tests were carried out on the filled fissure. Strength parameters were confirmed in a comprehensive consideration of the test data of the undisturbed expansive soil and the expansive soil with filled fissures (Table 4). The first layer of reddish brown clay was hard plastic, with a free expansion rate of $42 \%$, low permeability, and the lowest shear strength. The second layer of brown-yellow clay was hard plastic, with a free expansion rate of $56 \%$, low permeability, relatively developed fissures, and high shear strength. The third layer of brown clay and gray-green clay was hard plastic, with a free expansion rate of $93 \%$ and strong swelling characteristics, and shear strength equivalent to that of the previous layer. The fissures were very developed, and most of them were long-large fissures.

Table 4. Calculation parameters of expansive soils in the slope.

\begin{tabular}{ccc}
\hline Location & $c \mathbf{( k P a )}$ & $\boldsymbol{\varphi ( { } ^ { \circ } )}$ \\
\hline 0 to $3 \mathrm{~m}$ & 16 & 14 \\
3 to $7 \mathrm{~m}$ & 23 & 16 \\
Below $7 \mathrm{~m}$ & 23 & 17 \\
Filled fissure & 14 & 4 \\
\hline
\end{tabular}

Incorporating typical filled fissures into the model and calculating under the conditions closest to the real working conditions, it could be found that the safety factor of the slope was about 0.9 . The slope was in an unstable state. At the same time, under the same geometric model, soil parameters and groundwater conditions, the stability analysis of the homogeneous expansive soil slope without fissures was carried out. It was found that the safety factor of the slope was about 1.2, and the slope was not unstable. As shown in Figure 11, in a homogeneous expansive soil slope without fissures, the sliding surface is arc-shaped, extending from the top of the slope to the foot of the slope (Figure 11a). In the slope with fissures, the shape of the sliding surface is a broken line, which is comprised of vertical fissures in the top of the slope and the straight line-shaped sliding surface develops from the bottom of the vertical fissures to the foot of the slope (Figure 11b). The sliding surface shape is affected by the vertical fissures on the top of the slope and the slow-inclined long-large fissures in the slope, which is basically consistent with the actual failure characteristics of the landslide. 


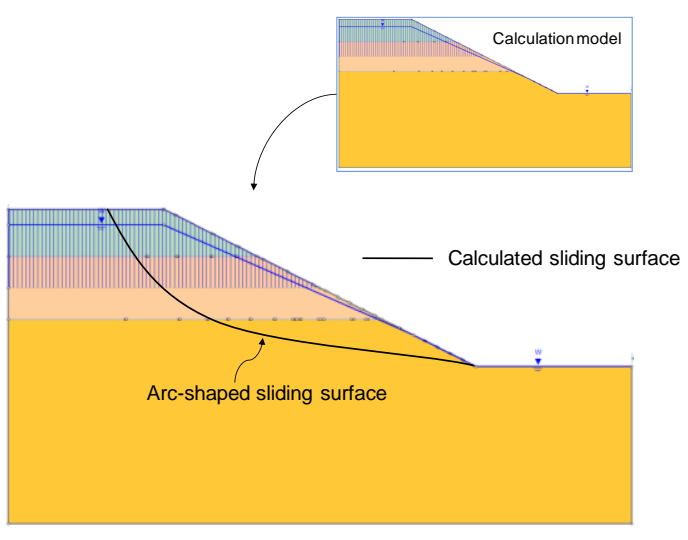

(a)

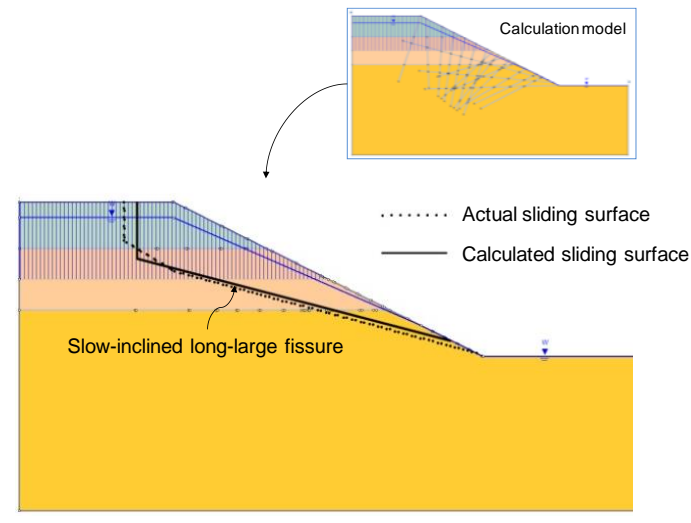

(b)

Figure 11. Calculate sliding surface and actual sliding surface. (a) Homogeneous expansive soil slope; (b) expansive soil slope with filled fissures.

\section{Conclusions}

Fissured expansive soils were widely distributed in the mid-route of the South-to-North Water Transfer Project in China. Most of the fissures were filled fissures, which were filled with the gray-green clay. The gray-green clay was a typical strong expansive soil, and its content of clay particles and hydrophilic minerals was extremely high. The long-large filled fissures controlled the stability of the deep expansive soil slope.

The limitations of the commonly used test methods for dealing with expansive soil filled fissures were analyzed, based on the conventional triaxial test sample preparation method; the mold was improved, the strong expansion fissure filler was manually placed in the sample, and the thickness and the inclination angle of the filled fissure were controlled. The layered filling-bevel cutting-refilling was the basic idea of the sample preparation device and method. A sample preparation device for triaxial test sample containing a filled fissure was designed.

Triaxial tests of the expansive soil with filled fissure were carried out. Samples were prepared with filled fissures with inclination angles of $15^{\circ}, 30^{\circ}$ and $45^{\circ}$, and with a thickness of $7 \mathrm{~mm}$, and a sample without filled fissures for comparison. After setting the filled fissures of gray-green strong expansive soil in the medium expansive soil matrix, it had a greater impact on the mechanical properties of the expansive soil, resulting in strength attenuation at various load levels in the triaxial tests. The strength attenuation was positively correlated with the inclination of the filled fissure. The strength parameters of expansive soils with filled fissures were basically stable, in which the cohesive force $c$ was about 12 to $15 \mathrm{kPa}$ and the internal friction angle $\varphi$ was about $3^{\circ}$ to $6^{\circ}$. The deformation characteristics of the samples had a tendency to develop from strain hardening to strain softening after setting the filled fissures, and it was most significant when the fissure was filled with a $45^{\circ}$ inclination angle. This provided parameters for the slope stability calculation of the actual project, and also provided a basis for the analysis of the strength of the filled fissure according to the geological survey on site, which was convenient for quickly predicting the possibility of landslide occurrence and the type, location and scale of the landslide.

The spatial distribution of the filled fissures in the slope was included in the model, and the strength parameters of the filled fissures were considered. The geological model of the slope with filled fissures was generalized, and a stability analysis method for the expansive soil slope with filled fissures was proposed. A typical landslide in the South-to-North Water Transfer Project was selected as an example to analyze the slope stability. It could be found that the safety factor of the slope was about 0.9 . The slope was in an unstable state. The sliding surface was affected by the vertical fissures on the top of the slope and the slow-inclined long-large fissures in the slope, and the shape of the sliding surface was a broken line, which was basically consistent with the actual failure characteristics of the landslide. 
Author Contributions: Conceptualization, H.L. and Z.D.; methodology, Z.D.; software, H.L.; validation, J.L., J.G. and S.C.; formal analysis, Z.D.; investigation, H.L. and J.G.; resources, J.L.; data curation, J.G.; writing-original draft preparation, Z.D.; writing-review and editing, H.L.; visualization, J.L.; supervision, S.C.; project administration, Z.D.; funding acquisition, Z.D. All authors have read and agreed to the published version of the manuscript.

Funding: This research was funded by the National Natural Science Foundation of China, grant number 41702337.

Conflicts of Interest: The authors declare no conflict of interest.

\section{References}

1. Ng, C.W.W.; Zhan, L.T.; Bao, C.G.; Fredlund, D.G.; Gong, B.W. Performance of an unsaturated expansive soil slope subjected to artificial rainfall infiltration. Géotechnique 2003, 53, 143-157. [CrossRef]

2. Alonso, E.E.; Gens, A.; Delahaye, C.H. Influence of rainfall on the deformation and stability of a slope in overconsolidated clays: A case study. Hydrogeol. J. 2003, 11, 174-192. [CrossRef]

3. Chen, F.H. Foundations on Expansive Soils; Elsevier: Amsterdam, The Netherlands, 1988.

4. Hou, T.-S.; Xu, G.-L.; Shen, Y.-J.; Wu, Z.-Z.; Zhang, N.-N.; Wang, R. Formation mechanism and stability analysis of the Houba expansive soil landslide. Eng. Geol. 2013, 161, 34-43. [CrossRef]

5. Ito, M.; Azam, S. Engineering properties of a vertisolic expansive soil deposit. Eng. Geol. 2013, 152, 10-16. [CrossRef]

6. Zhan, T.L.; Ng, C.W.; Fredlund, D.G. Field study of rainfall infiltration into a grassed unsaturated expansive soil slope. Can. Geotech. J. 2007, 44, 392-408. [CrossRef]

7. Cheng, Y.; Wang, S.; Li, J.; Huang, X.; Li, C.; Wu, J. Engineering and mineralogical properties of stabilized expansive soil compositing lime and natural pozzolans. Constr. Build. Mater. 2018, 187, 1031-1038. [CrossRef]

8. Chertkov, V.Y. Using Surface Crack Spacing to Predict Crack Network Geometry in Swelling Soils. Soil Sci. Soc. Am. J. 2000, 64, 1918-1921. [CrossRef]

9. Chertkov, V.Y.; Ravina, I. Modeling the Crack Network of Swelling Clay Soils. Soil Sci. Soc. Am. J. 1998, 62, 1162-1171. [CrossRef]

10. Al Fouzan, F.; Dafalla, M.A. Study of cracks and fissures phenomenon in Central Saudi Arabia by applying geotechnical and geophysical techniques. Arab. J. Geosci. 2013, 7, 1157-1164. [CrossRef]

11. Li, X.-W.; Wang, Y.; Yu, J.-W.; Wang, Y.-L. Unsaturated expansive soil fissure characteristics combined with engineering behaviors. J. Central South Univ. 2012, 19, 3564-3571. [CrossRef]

12. Li, J.; Zhang, L.; Li, X. Soil-water characteristic curve and permeability function for unsaturated cracked soil. Can. Geotech. J. 2011, 48, 1010-1031. [CrossRef]

13. Hu, X.W.; Li, Q.; Zhao, Z.S.; Kong, D.F. Mechanical properties of fissured clay. Chin. J. Geotech. Eng. 1994, 16, 81-88.

14. Chen, T.-L.; Zhou, C.; Wang, G.-L.; Liu, E.-L.; Dai, F. Centrifuge Model Test on Unsaturated Expansive Soil Slopes with Cyclic Wetting-Drying and Inundation at the Slope Toe. Int. J. Civ. Eng. 2017, 16, 1341-1360. [CrossRef]

15. Mutaz, E.; Dafalla, M.A. Chemical analysis and X-ray diffraction assessment of stabilized expansive soils. Bull. Int. Assoc. Eng. Geol. 2014, 73, 1063-1072. [CrossRef]

16. Chaduvula, U.; Viswanadham, B.V.S.; Kodikara, J.; De, A.; Reddy, K.R.; Yesiller, N.; Zekkos, D.; Farid, A. Desiccation Cracking Behavior of Geofiber-Reinforced Expansive Clay. Geo-Chicago 2016 2016, 271, 368-377. [CrossRef]

17. Zong, Y.; Chen, D.; Lu, S. Impact of biochars on swell-shrinkage behavior, mechanical strength, and surface cracking of clayey soil. J. Plant Nutr. Soil Sci. 2014, 177, 920-926. [CrossRef]

18. Chaduvula, U.; Viswanadham, B.; Kodikara, J. A study on desiccation cracking behavior of polyester fiber-reinforced expansive clay. Appl. Clay Sci. 2017, 142, 163-172. [CrossRef]

19. Kong, L.-W.; Wang, M.; Guo, A.-G. Effect of drying environment on engineering properties of an expansive soil and its microstructure. J. Mt. Sci. 2017, 14, 1194-1201. [CrossRef]

20. Al-Dakheeli, H.; Bulut, R.; Clarke, C.R.; Nevels, J.B. Hydro-Mechanical Analysis of Crack Initiation in Expansive Soils. PanAm Unsatur. Soils 2017 2018, 303, 332-341. [CrossRef]

21. George, A.M.; Chakraborty, S.; Das, J.T.; Pedarla, A.; Puppala, A.J. Understanding Shallow Slope Failures on Expansive Soil Embankments in North Texas Using Unsaturated Soil Property Framework. PanAm Unsatur. Soils 2017 2018, 302, 206-216. [CrossRef] 
22. Liu, H.Q.; Yin, Z.Z. Test study of influence of crack evolution on strength parameters of expansive soil. Rock Soil Mech. 2010, 31, 727-731.

23. Hu, B.; Gong, B.W.; Cheng, Z.L. Test study of shear strength of fissure-plane in Nanyang expansive soil. Rock Soil Mech. 2012, 33, 2942-2946.

24. Bao, C.G.; Liu, T.H. Shear strength of swelling soil in Nanyang district, Henan province. J. Yangtze River Sci. Res. Inst. 1990, 7, 1-8.

25. Bishop, A.W. The use of the Slip Circle in the Stability Analysis of Slopes. Géotechnique 1955, 5, 7-17. [CrossRef]

26. Chen, Y.; Lin, H. Consistency analysis of Hoek-Brown and equivalent Mohr-coulomb parameters in calculating slope safety factor. Bull. Int. Assoc. Eng. Geol. 2018, 78, 4349-4361. [CrossRef]

27. Li, Y.; Qian, C.; Fu, Z.; Li, Z. On Two Approaches to Slope Stability Reliability Assessments Using the Random Finite Element Method. Appl. Sci. 2019, 9, 4421. [CrossRef]

28. Khan, M.S.; Hossain, M.; Ahmed, A.; Greenwood, K.; Shishani, A. Parametric Study on Slope Stability Using Recycled Plastic Pin. Geo-Risk 2017 2017, 283, 226-236. [CrossRef]

29. Khan, M.S.; Nobahar, M.; Khan, M.S.; Amini, F. Rainfall Induced Shallow Slope Failure over Yazoo Clay in Mississippi. PanAm Unsatur. Soils 2017 2018, 302, 153-162. [CrossRef]

30. Qi, S.; Vanapalli, S.K. Hydro-mechanical coupling effect on surficial layer stability of unsaturated expansive soil slopes. Comput. Geotech. 2015, 70, 68-82. [CrossRef]

31. Mugagga, F.; Kakembo, V.; Buyinza, M. A characterisation of the physical properties of soil and the implications for landslide occurrence on the slopes of Mount Elgon, Eastern Uganda. Nat. Hazards 2011, 60, 1113-1131. [CrossRef]

32. He, P.; Li, S.; Xiao, J.; Zhang, Q.-Q.; Xu, F. Shallow Sliding Failure Prediction Model of Expansive Soil Slope based on Gaussian Process Theory and Its Engineering Application. KSCE J. Civ. Eng. 2017, 22, 1709-1719. [CrossRef]

33. Oh, W.T.; Vanapalli, S.K. Influence of rain infiltration on the stability of compacted soil slopes. Comput. Geotech. 2010, 37, 649-657. [CrossRef]

34. Li, R.J.; Yan, R.; Liu, J.D.; Shao, S.J. A new practicable approach to the stability analysis of unsaturated expansive soil slope. Disaster Adv. 2013, 6, 33-43.

35. Zuo, C.-Q.; Chen, J.-P. The stability analysis of expansive slope in Jing-Yi Expressway. J. Zhejiang Univ. A 2007, 8, 270-274. [CrossRef]

36. Lu, D.J. Geo-engineering property and slide mechanism of highly expansive soil of Nanyang on mid-route of South-North Water Transfer Project. Master's Thesis, University of Chinese Academy of Sciences, Beijing, China, 2013.

37. Zhao, L. Study on fissure characteristics and its impact on slope stability of expansive soil. Ph.D. Thesis, Yangtze River Scientific Research Institute, Wuhan, China, 2012.

38. Zhang, J.J.; Gong, B.W.; Hu, B.; Zhou, X.W.; Wang, J. Study of evolution law of fissures of expansive clay under wetting and drying cycles. Rock Soil Mech. 2011, 32, 2729-2734.

(C) 2020 by the authors. Licensee MDPI, Basel, Switzerland. This article is an open access article distributed under the terms and conditions of the Creative Commons Attribution (CC BY) license (http://creativecommons.org/licenses/by/4.0/). 